\title{
The Multidimensional Disadvantages of Centrist Parties in Western Europe
}

\author{
Roi Zur
}

\begin{abstract}
Empirical evidence suggests that most parties in Western Europe do not take cen-trist policy positions, despite the centripetal force of the voter distribution. While most scholars focus on the reasons for parties' divergence, this paper focuses on the reasons for the electoral failures of parties that take centrist LeftRight positions. This paper demonstrates that centrist parties, such as the British Liberal Democrats and the German FDP, suffer from multidimensional disadvantages. Using the 2014 Chapel Hill Expert Survey and the European Election Studies surveys, I show that centrist parties are systematically disadvantaged regarding non-policy issues, such as competence, integrity, and party unity (i.e. valence issues). Second, I demonstrate that given their valence image there is no set of policy positions centrist parties can take to substantially improve their vote shares. While (Left-Right) centrist parties usually take positions that are far more supportive of European integration than the mass publics, moderating their positions is expected to increase centrist parties' vote-share but not as much as it is expected to increase the vote-share of Christian Democratic parties. These results have important implications for the study of politi-cal representation, electoral campaigns, and parties' policy shifts.
\end{abstract}

Keywords Centrist parties $\cdot$ Liberal parties $\cdot$ Voting $\cdot$ Valence issues $\cdot$ European ParliamentElections $\cdot$ Party strategies $\cdot$ Positional issues 


\section{Introduction}

Why are centrist parties, for the most part, much smaller than their counterparts on the moderate Left and Right? Despite holding very popular Left-Right positions, centrist parties, predominantly members of the Liberal party family, such as the British Liberal-Democrats (LibDems) and the German Free Democratic Party (FDP) fail to translate their popular Left-Right positions to high vote-shares. The data used in this paper show that more than $26 \%$ of voters in the European Parliament Election study place a centrist party as the closest to their preferred Left-Right position, but centrist parties received only $10 \%$ of the votes. Put differently, given the salience of the Left-Right dimension and the distribution of party positions, the Downsian (1957) framework expects centrist parties to be more electorally successful than they are. Moreover, empirical research has shown that most European parties diverge from the center of the Left-Right dimension, despite the strong centripetal force of the voter distribution (e.g. Adams and Somer-Topcu 2009). This limited congruence between parties' non-centrist policies and voters' demand for centrist ideology has been a major puzzle in the study of democratic representation (Adams et al. 2005, 2020; Bølstad and Dinas 2017; among others).

To better understand the limited electoral success of centrist parties, this paper studies the multidimensional disadvantages encountered by centrist parties. ${ }^{1}$ First, I argue that most centrist parties are disadvantaged with respect to non-positional attributes. That is, voters prefer voting for parties that are more distanced from their ideological preference because they perceive centrist parties as lacking valence attributes such as competence, integrity, leadership ability, and party unity. These valence attributes have been linked to parties' electoral success (Clark 2009; Clark and Leiter 2014).

A second disadvantage that centrist parties encounter is that, given their unfavorable valence image, they have no feasible strategy that can substantively increase their vote-shares. This is true for both unidimensional positional party competition and (although to a lesser extent) for multidimensional positional competition. On the one hand, their Left-Right positions resemble their optimal (vote maximizing) positions, and thus they cannot gain many votes by altering these positions. On the other hand, centrist-Liberal parties' positions are much more pro-EU than the skeptical mass publics, so that moderating these positions could potentially yield vote-share increase for centrist parties, but similar moderation would yield a larger vote-share increase for the major Right-wing parties.

A third disadvantage of centrist parties is that their only available strategy toward a substantive vote-share growth is improving their valence image. Yet, their perceived negative valence image relative to major-Left and major-Right parties would make this strategy less successful than similar strategy by their competitors.

\footnotetext{
1 Because elections to the European Parliament do not end with government formation (unlike national elections), I assume that parties are vote-maximizers, i.e., they do not pursue alternative goals such as maximizing policy payoffs, participation in governing coalitions, or the duration of their survival.
} 
To support these arguments, I examine both unidimensional and three-dimensional voting models of the 2014 European Parliament (EP) elections. EP elections provide a great opportunity to test the multidimensional disadvantages of centrist parties because they are regarded as second-order elections (Reif and Schmitt 1980; Hix and Marsh 2007), in which issues such as immigration and European integration are salient (Hobolt et al. 2009; Hobolt and Spoon 2012; Hong 2015; Hobolt and de Vries 2016). Moreover, second-order elections free voters from considerations such as government formation in their country or coalition management. Therefore, EP elections are considered to be elections in which voters vote more sincerely than national elections. In the context of EP elections, centrist parties should be able to meet the Downsian expectation. Yet, even under these promising conditions centrist parties still lose votes due to their negative valence image. Additionally, even under very weak set of assumptions, centrist parties are unable to compensate for their negative valence by taking vote-maximizing positions on Left-Right ideology, on immigration, and on EU integration issues. Moreover, mathematical simulations show that centrist parties' best strategy for vote-share growth is to improve their valence image. Yet, even if they were able to do so, they cannot grow as much as major-Left and major-Right parties can by improving their valence.

This paper contributes to the growing literature explaining party competition in Western Europe. It shows that centrist-Liberal parties' strategies are substantially different from those of other mainstream or established parties. It implies that voters judge Liberal parties differently than they judge parties on the moderate-Left or moderate-Right, and that Liberal parties should behave differently in election campaigns than their main competitors. Moreover, unlike previous research that focuses on party competition over one or two overarching dimensions, this paper shows that party competition over multiple issues and parties' valence image are needed for explaining the electoral failures of centrist parties. Lastly, this paper contributes to the understanding of the causes and consequences of party policy shifts by showing that parties' valence image is an important factor in representation of voters' preferences.

\section{The Systematic Disadvantages of Centrist Parties}

Centrist parties in Western democracies often fail to capitalize on their popular Left-Right positions and become major vote-winning parties (Close and Delwith 2019; Zur 2019a). Centrist parties' electoral results are especially puzzling given the distribution of voter preferences (Adams and Somer-Topcu 2009) and the positions of rival parties (Polk et al. 2017). Put differently, based on the spatial theory of voting (Downs 1957), centrist parties enjoy fruitful conditions to win a large percentage of the votes in both national and EP elections. How, then, we can reconcile these favorable spatial conditions with centrist parties' lack of electoral success?

The idea that the proximity model presented by Downs (1957) does not completely capture voting behavior is well established in the literature. Many factors have been shown to motivate voting for parties that advocate policies that are 
distanced from the voter's preferred policy position. Voters consider post-election coalitions (Kedar 2005; Schofield and Sened 2006), thus voting for parties that are more extreme than their most proximate party. Additionally, abstention from voting (Adams et al. 2005) and discounting parties' claims (Merrill and Grofman 1999) distort the Downsian proximity model. Another explanation for the observation that voters might prefer parties other than the most proximate one is that voters consider the direction parties push public policy toward (e.g. Matthews 1979; Macdonald et al. 2007; Rabinowitz and Macdonald 1989) or the category parties belong to on the Left-Right continuum (Bølstad and Dinas 2017). While this is a well-developed literature, it does not explain why centrist parties are systematically disadvantaged. ${ }^{2}$

Centrist parties, I argue, suffer from systematic disadvantage due to their perceived valence image relative to other parties. Negative valence image both decreases centrist parties' ability to gain votes and limits their ability to strategically announce policy positions that improve their electoral prospect. Valence is defined in this paper as attributes that voters almost unanimously approve (Stokes 1963, 1992), including party's image with respect to competence, honesty, and leadership ability. Other valence attributes are non-positional characteristics of parties, such as their campaign effectiveness, recruitment of committed activists, or ability to raise contributions, which in turn can be used to burnish parties' valence images during electoral campaigns. Given the non-conflictual nature of valence, all parties are motivated to present an image of holding more rather than less of these attributes.

Numerous studies have documented the relationship between valence and vote choice. Abney et al. (2013) find that late in the campaign period, changes in parties' image of valence are related to their electoral success. The works of Michael Clark (2009, 2013; Clark and Leiter 2014) find that European parties' vote-shares decrease as a function of increase in negative valence-related news reports. Green and Jennings $(2012,2017)$ demonstrate the importance of issue ownership and image of competence for electoral success. In US Congressional elections, the vote-shares of incumbent candidates increase as their valence increases relative to the challengers' valence (Mondak 1995; Stone 2017; Stone and Simas 2010; Stone et al. 2004).

Previous research documents centrist-Liberal parties' valence disadvantages. For example, Huckfeldt et al. (2005) argue that small parties (mostly centrist parties such as the FDP) tend to suffer from long-term non-policy related disadvantage with respect to patterns of social agreement. Centrist parties also tend to be junior coalition partners in many West European countries. Joining governing coalitions as the junior partner limits centrist parties' ability to enact their election promises (Klüver and Spoon 2020) which in turn might hurt their image of competence and integrity. Additionally, recent experimental evidence by Johns and Kölln (2020) connects parties' policy positions with their image of competence, where parties slightly to the right or left are perceived by voters as more competent than parties at the pure center. Lastly, Zur (2019a) argues that centrist parties are valence disadvantaged because they tend to be involved in national scandals and are less able to elect

\footnotetext{
2 I show in the appendix, these voters' considerations help to improve the general explanation about proximity voting in the EP elections, but they do not alter the substantive argument in this paper.
} 
popular leaders. The valence disadvantage of centrist parties in national elections should also be translated to the EP elections. If centrist parties are indeed perceived by voters as holding weaker qualities of competence, integrity, or unity, voters will not support them in elections for the EP. This argument can be tested with the following hypothesis:

Hypothesis 1 Controlling for their policy positions, centrist parties' valence images are negative, relative to other parties in their country.

While all parties can suffer from negative valence image, centrist parties are unique in their lack of strategical positional opportunities to compensate for their non-positional image. Parties, knowing that their valence image is negative, can shift their policy positions toward the crowded center, thus compensating voters in terms of policy-based utility (Adams and Merrill 2009). Moderation of policy positions have been shown to be a useful strategy for some political parties (Ezrow 2005) and related to deterioration of their valence image (Clark 2014). Adams et al. (2005) find that all parties' vote-maximizing positions are near the center of the Left-Right distribution, but parties do not fully converge to the center. Yet, centrist parties, distinctly from parties on the wings, are already perceived as moderate. Therefore, the second disadvantage encountered by centrist parties is that they cannot find any Left-Right position that will significantly increase their vote-share. From this argument the following hypothesis follows:

Hypothesis 2 Centrist parties cannot substantially increase their expected vote-share by changing their Left-Right position.

To fully explain the mechanism that allows high-valence non-centrist parties to gain votes by moving toward the center I emphasize the dynamic of party competition with two components: a general unidimensional policy component and non-policy (valence) component. If voter distribution on the Left-Right is (as the data here and the common knowledge in the literature show) single-peaked around the middle of the scale, the intervals of the scale close to the position of centrist parties are flatter than those of non-centrist parties. Therefore, even before considering valence, by changing their policy positions centrist parties cannot do as well as non-centrist parties. For example, if a centrist party moves left from 5.5 to 5 on a $0-10$ Left-Right scale, the number of votes it gains on the left is similar to the number of votes it loses on the right. A non-centrist party on the other hand, can gain more votes than it loses by a comparable shift to its Left-Right position. That is, by moving from 7 to 6.5 , a right-wing party will gain more votes at the center than it would lose on its right flank. Then, right wing parties can move even further toward the center, meaning they can win additional votes, until they reach a point where changing positions does not yield additional votes. Thus, right-wing parties will position themselves to the right of centrist parties, but closer than their original position (Adams et al. 2020). 
The valence component of this competition makes the difference in vote gains even larger when comparing the two parties above. If the right-wing party is valence advantaged relative to the centrist party, by moving closer to the centrist party, the right-wing party can win the votes of the voters who are indifferent between its (new) position and the position of the centrist party. On the other hand, being valence disadvantaged, the centrist party must sufficiently differentiate its position from the position of its competitors both on its right and left side (Spoon 2011; Zur 2019b).

While Hypothesis 2 pertains to the overarching Left-Right dimension, voters in EP elections tend to be motivated by issues beyond Left-Right politics. The issue of European integration and EU powers are increasingly salient in EP elections (Bakker et al. 2018, 2020; Hobolt et al. 2009; Hobolt and Spoon 2012; Hong 2015; Hobolt and de Vries 2016). Moreover, attitudes toward immigration influence EP voting decisions (Bakker et al. 2018; Hobolt and Tilly 2016). The analyses below suggest that, on both these issues, centrist parties take (on average) less popular positions than on the Left-Right spectrum. While centrist parties are perceived as the most proximate party to the preference of a large segment of the electorate on Left-Right, the segment of the electorate that perceives centrist parties as the most proximate to their position on immigration and European integration is rather small.

Centrist parties' positions on immigration and European integration disadvantage them in two ways in EP elections. First, these dimensions are less salient than the Left-Right dimension (even in EP elections). By moving to their votemaximizing position centrist parties' vote-share should increase, but not to the extent that non-centrist parties' vote-share increases when they moderate their Left-Right position. To understand this argument, think of an electorate that punishes (in terms of probability of voting) parties for being distant from them on two dimensions-Left-Right and immigration. If the punishment is similar for both dimensions and the distribution of preferences on both dimensions is similar, changing parties' position on both dimensions will yield similar gains (holding everything else constant). This situation is fruitful for centrist parties as gains on the second dimension will compensate for the lack of gains on the Left-Right dimension. However, when punishment is larger on one dimension relative to the other, changes on the second dimension are followed by smaller changes in expected vote-shares. Unfortunately for centrist parties, the empirical evidence in this paper show that the immigration and European integration dimensions are less electorally salient, so that moving to vote-maximizing positions on all three dimensions only slightly increases their vote-share.

Second, given that centrist parties' valence image is negative, moving to their vote-maximizing positions on EU integration or immigration would increase their vote-share, but not enough to overcome their major rivals. Even if a larger segment of the electorate would find centrist parties' positions the most favorable, voters would still discount these positions. Taking these two components together, the third hypothesis is: 
Hypothesis 3 Centrist parties can increase their expected vote-share by shifting their positions to vote-maximizing positions in a three-dimensional space, but not as much as high-valence parties.

The third disadvantage encountered by centrist parties is that their only strategy toward a substantive vote-share growth is improving their valence image. Yet, centrist parties must close a very large gap with respect to valence relative to major-Left and major-Right parties. Thus, even if their valence image is greatly improved, this strategy would be somewhat insufficient. Put differently, if a centrist party's valence image is improved by the same magnitude a major-Right party's valence is improved; the former will gain less additional votes than the latter. To fully grasp this argument, think of an extreme case where the valence characteristics of one party are exceptionally bad; a party that is perceived as the most corrupt, extremely incompetent, and a danger to national security. Such party, even if it can improve its valence image to some extent, will still be valence disadvantaged relative to the other parties, and therefore can only marginally improve its vote-share. On the other hand, if a party is just slightly valence-disadvantaged, small improvement to its valence image might make it valence-neutral or even valence advantaged relative to all other parties. For example, think of how badly perceived the German FDP is relative to the CDU and SPD (Zur 2017). By improving its valence, the FDP can increase its expected vote-share by so much. The SPD, however, is just slightly valence-disadvantaged relative to the CDU, and by improving its valence image can gain a great deal of new votes. From this logic a testable hypothesis follows:

Hypothesis 4 Given their exceptionally unfavorable valence image, centrist parties can only modestly increase their expected vote-share by improving their valence image.

\section{Data and Measurement}

The data used in this article come from two sources. Data about parties' positions and ideology come from the Chapel Hill Expert Survey (CHES) (Polk et al. 2017) and data about voters come from the European Election Studies (EES) (Schmitt et al. 2015). These data sources are useful because CHES and EES provide similar set of positional issue placements for both parties and voters. The coordination between CHES and EES in their 2014 surveys allows me to construct a multidimensional space of party competition. Following Bakker et al. (2018), and based on the theoretical argument above, I construct a three-dimensional space where the first dimension is general Left-Right, the second is the level of immigration restriction, and the third is the level of European integration. ${ }^{3}$ While the EES and CHES include other policy questions, I limit the policy space to these three dimensions as

\footnotetext{
${ }^{3}$ The correlations between respondents' self-placements on these dimensions are sufficiently low to treat them as three independent dimensions and are shown in the appendix.
} 
they have the largest effect on voting. That is, they are the most salient dimensions. Moreover, as shown below, the overarching, general ideology, Left-Right dimension is the most salient of the three.

In the voting models analyzed below, the dependent variable is the respondent's reported vote choice in the 2014 EP elections. The EP elections are well-suited for testing the multidimensional disadvantages of centrist parties because they are often considered as second-order elections in which voters express their sincere preferences (Reif and Schmitt 1980; Hix and Marsh 2007). In the EP elections, vote choice is often driven by a different set of considerations than national elections, and these considerations are additional to the general Left-Right dimension. Mostly, there is increasing evidence that issues related to the European Union are more prominent in EP elections (Bakker et al. 2018; Hobolt et al. 2009; Hobolt and Spoon 2012; Hong 2015; Hobolt and de Vries 2016). In addition, the issue of immigration restriction has been shown to be a major consideration in voters' EP voting decision (Bakker et al. 2018, 2020; Hobolt and Tilly 2016).

Using these data, I examine voting models in 11 West European countries ${ }^{4}$ in which there is at least one centrist party. Centrist parties are defined as parties that are: (1) perceived by voters as taking a Left-Right position between the major-Left and the major-Right parties, and (2) belong to either the Liberal or the agrarian party families. ${ }^{5}$ This definition of centrist parties is useful for the study of voting behavior because it allow me to differentiate between the historical and path-dependent disadvantage of Liberal and agrarian parties, based on the first part of the definition (Huckfeldt et al. 2005). At the same time, this definition does not limit centrist parties to either Liberal or agrarian. Major parties are defined as the historically largest party on each side of the Left-Right spectrum. Green parties are referred to as a specific category, while all other parties are defined by their position on the Left-Right scale and named "other Left" or "other Right". To understand these groups of parties, take the UK for example, where Labour is referred to as major-Left, the Conservatives as major-Right, the Liberal-Democrats as center, UKIP as "other Right", and SNP as "other Left". In the data used in this paper, 11 parties are defined as major-Left and 11 are major-right, 14 parties belong to the center category, 10 are green parties, 15 are minor Left parties and 18 are minor Right parties. Parties that received less than $1 \%$ of the votes or no seats are excluded from the analysis. The total number of reported vote choices is 6,116 , and the total number of voter-party observations is 44,831 .

The independent variables are measured as the linear absolute difference between the respondent's self-placement and the experts' mean placements of each party on each focal issue (general Left-Right, immigration, EU integration). Both voters and experts' positions are measured on a 0 to 10 scale, where 0 indicates extreme

\footnotetext{
4 These countries are Austria, Belgium, Denmark, Finland, France, Germany, Luxembourg, the Netherlands, Spain, Sweden, and the United Kingdom. Because the EES code Belgium's Flanders and French parties separately, the analysis below includes only the French specking parties of Belgium, the substantive results below hold for both Flanders (shown in the appendix) and French parties.

${ }^{5}$ In robustness checks I have excluded the agrarian parties and included only liberal parties in the centrist party group. The substantive results hold.
} 

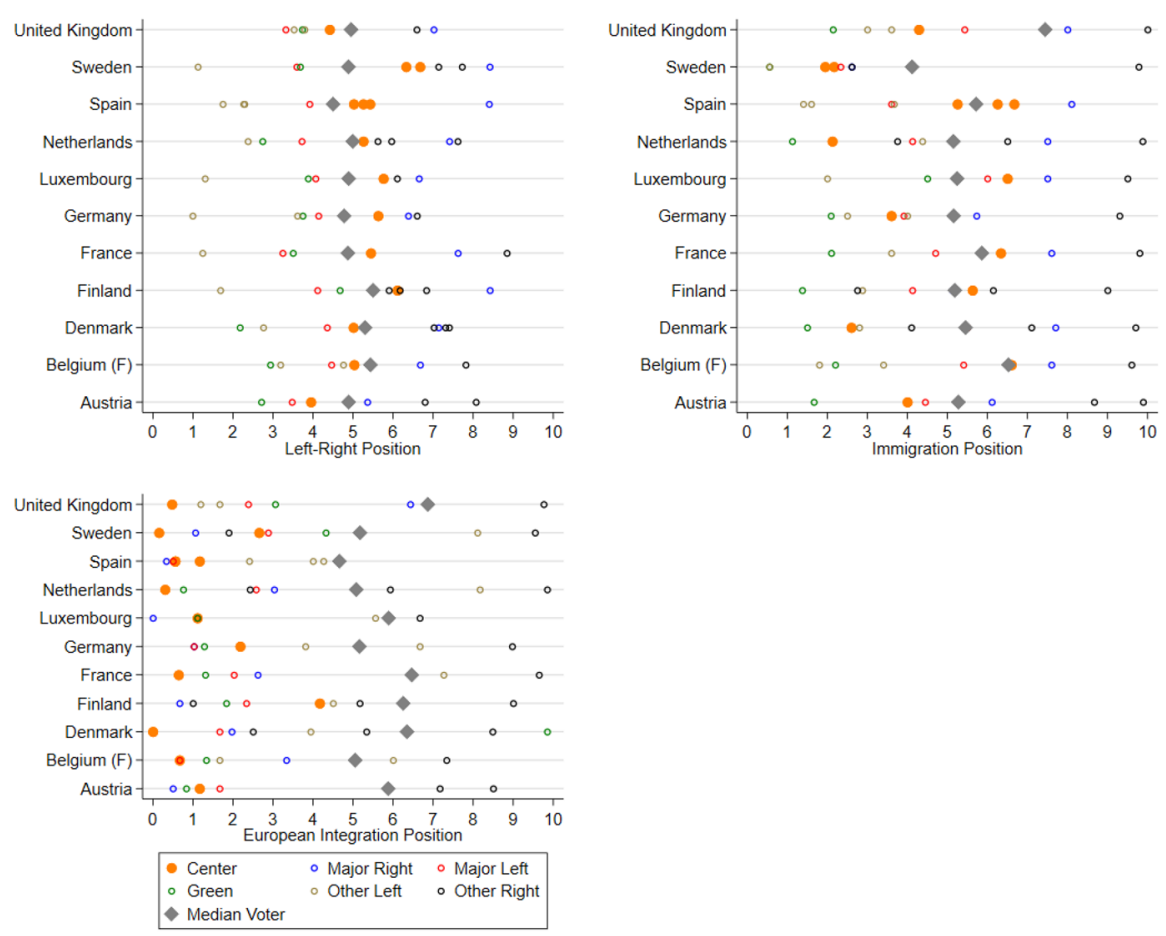

Fig. 1 Parties' and Median Voters' Positions. Note This Figure shows parties' mean Left-Right perceived position (by voters), experts' placements of the parties on immigration restrictiveness (top-right panel) and the European integration (bottom panel), and the position of the median voter in each country. Voters' preference distributions and the list of parties' names and groups is presented in the appendix

left, less restrictive immigration policy, and more European integration. ${ }^{6}$ Figure 1 presents the positions of both parties and median voters on the three dimensions of interest. On average, centrist parties take very popular positions (in terms

\footnotetext{
${ }^{6}$ These proximity variables are based on the following questions in EES and the corresponding question in CHES:
}

- General left-right (QPP12): In political matters people talk of "the left" and "the right". What is your position? Please use a scale from 0 to 10 , where 0 means "left" and 10 means "right". Which number best describes your position?

- Immigration (QPP17.6): (a scale from 0 to 10 , where 0 means you are 'fully in favor of a restrictive policy on immigration', and 10 means 'you are fully opposed to a restrictive policy on immigration'. For convenient I have reordered the scale in the opposite direction.

- European integration (QPP18): Some say European unification should be pushed further. Others say it already has gone too far. What is your opinion? Please indicate your views using a scale from 0 to 10 , where 0 means unification 'has already gone too far' and 10 means it 'should be pushed further'. What number on this scale best describes your position?

To maximize variation in the categorical scales I multiply voters' self-placements by a randomly assigned uniform distribution ranging from --0.5 to 0.5 . For example, all voters who self-placed at 5 had equal probability to be treated as if they self-placed between 4.5 and 5.5 on the $0-10$ scale. 
of proximity to the median voter and in terms of proximity to a large share of the electorate) on both the Left-Right dimension and the immigration issue, but their position on European integration is unpopular. That is, only a small segment of the electorate reports a position that is the most proximate to the position of the centrist party. In the countries examined in this paper, the percentage of voters who placed a centrist party as the closest to their own Left-Right ideal point ranges between $16.2 \%$ (in Denmark) and $41.4 \%$ (in Luxembourg), with an average of $26.3 \%$. This small distance between voters and parties' positions shapes the expectation and puzzle of this paper. Centrist parties should be electorally successful given their popular Left-Right position and the high salience of the Left-Right dimension.

Parties that are centrist on Left-Right take less popular positions on the issue of immigration. Only $8.9 \%$ of the voters examined in this paper placed themselves as closest to the position of the centrist party as perceived by the experts, with a range of $4.8 \%$ (in Sweden) to $13.3 \%$ (in Germany). Lastly, the positions of centrist parties on EU integration are clearly unpopular. Parties that are centrist on Left-Right take positions that are typically far away from those of the median voter in their country. All centrist parties (on Left-Right) are well to the left of the median voter on European integration. That is, centrist parties support the EU more extensively than the public opinion. Only $4.8 \%$ of voters reported a position that was closest to the centrist party's position in their country, ranging from $0.8 \%$ (in Austria) to $11.2 \%$ (Luxembourg). Figure 1 shows that on Left-Right, it will be challenging for centrist parties to take more popular positions than their current positions, and on other issues they will have to change their positions significantly to become popular on other issues. This visual distribution of parties suggests that centrist parties can grow their vote-shares by altering their immigration or EU integration, but not by altering their Left-Right position.

In addition to the proximity variables, the models below include party-specific coefficients that proxy voters' evaluation of parties' valence images. Following Adams et al. (2005) party-specific coefficients have been used frequently to model how non-policy related characteristics of parties (i.e. valence) affect their expected vote-shares. These coefficients measure the (dis)advantage parties receive from their valence image, independent of their policy positions. These authors discuss the methodological advantages and the relative simplicity of using the party specific coefficients in the conditional logit framework. ${ }^{7}$ They demonstrate that because these coefficients are choice (party) specific, rather than chooser (voter) specific, they are largely unaffected from the variance in chooser's characteristics, and thus are appropriate to proxy non-policy characteristics of the parties. In addition, party specific coefficients have been used repeatedly in the literature to proxy parties' valence images (see Adams et al. 2020 for a review).

\footnotetext{
7 The conditional logit framework has another advantage over other models as it provides estimates of vote-choice probabilities that incorporate not only the spatial proximity of voters to the party, but the relative probability of voting for the focal party over any other party, conditioned on the proximity to any other party in the model (e.g. Adams et al. 2005; Schofield and Sened 2006).
} 
Hypothesis 1 is tested using conditional logit models based on both the unidimensional (general Left-Right) and multidimensional vote choice rules. After testing Hypothesis 1, I use mathematical simulations to test Hypotheses 2-4 (see similar methodological approach in Adams and Merrill 1999, 2000, 2005; Adams et al. 2005; Alvarez and Nagler 1998, among others). In these simulations, voters' decision rules are represented as probabilistic functions of their proximity to each party along each dimension and the valence attributes estimated in the models testing Hypothesis 1. Then, the probability of each individual respondent voting for each party is calculated in order to compute each party's expected vote-share. In the next stage, I calculate the counterfactual change of parties' expected vote-shares as a result of either change in a party's policy position or its valence image. For example, given the unidimensional voting model presented below (Table 1), I estimate in the first stage that the German CDU/CSU are expected to receive 36.6 percent of the respondents' votes (relative to the actual result of 35.4 percent) when taking its observed Left-Right position (5.92 on a $0-10$ scale). Then, I calculate how its expected vote-share changes when taking every possible position on the Left-Right dimension (with all other parties' positions fixed at their announced position) and find that its vote-maximizing position is at 4.89 , where the CDU/CSU can increase its vote-share to 39.71 percent.

These simulations estimate how parties' vote-shares will change under a counterfactual scenario in which everything except the variable of interest is held constant. Based on the estimated salience of ideological proximity and parties' valence image, I simulate three counterfactual scenarios. First, I simulate parties' counterfactual vote-share increase due to change in their Left-Right policy position (as perceived by experts). ${ }^{8}$ In this scenario, each party unilaterally changes its policy position along the Left-Right scale, while all other parties' Left-Right positions and voters' decision rules are fixed. Then, a party's vote-maximizing position is defined as the Left-Right position which maximizes its expected vote-share. Similarly, the second scenario simulates by how much parties' vote-share increases if the party takes its vote-maximizing positions on all three dimensions. These two sets of simulations test Hypotheses 2 and 3, respectively.

I emphasize that these simulations are a hard test for Hypotheses 2 and 3. In these simulations, parties are free to alter their positions without any constrains or punishment to their valence attributes. This is a hard test for the theory because previous research has shown that parties rarely try to significantly change their policy positions (Dalton and McAllister 2015). Even when parties try to alter their positions, voters either ignore their new positions (Adams 2012; Adams et al. 2011) or discount new positions if they perceive parties' messages as vote-seeking (FernandezVazques 2019). Moreover, voters may punish parties in terms of valence when they believe parties change their positions in order to increase their vote-share (Tomz and Van Houweling 2012).

\footnotetext{
${ }^{8}$ In robustness checks I have repeated these simulations using voters' mean perceived position of the parties, and three-dimensional scaling of both parties' and voters' positions. The results of these simulations support the same substantive conclusions presented in this paper.
} 
The third scenario tests Hypothesis 4. I simulate how realistic changes in parties' non-positional (valence) attributes are related to their counterfactual electoral growth. I compute the parties' counterfactual vote-share increase from improving their valence image by one unit. That is, I simulate the vote-share increase from the observed valence differential between two parties to a counterfactual where one party has a unit-larger valence advantage. For example, if two parties are equal in their valence image (i.e. voters' choice between them is based on proximity alone) in the observed model, I simulate how their vote-share changes if one of the parties increases its valence advantage from 0 to 1 (in natural logarithm terms), making voters who are indifferent between the parties on positional issues about 70 percent more likely to vote for the valence advantaged party. The one-unit increase of valence image is a realistic value as it is the observed centrist party's valence change between one national election to the next (Zur 2019a).

\section{Results}

Tables 1 and 2 present country specific models in which the dependent variable is the respondent's reported vote choice in the 2014 EP elections. In both tables the coefficients are calculated from a conditional logit model and presented in odds ratio form. These coefficients imply that on the proximity variables, smaller numbers represent higher issue salience. As the coefficient decreases, the electoral punishment for divergence between voters and parties increases. Note that for all countries except the UK these models show that the overarching Left-Right dimension is more salient than the two other dimensions.

The valence coefficients are interpreted as the change in probability of voting for a focal party relative to the baseline category (centrist party). For example, when the coefficient equals 2 a voter who is indifferent between the centrist party and the focal party on positional issues is twice as likely to vote for the latter over the former.

Table 1 presents models in which voters' decision rules are a function of Left-Right proximity and parties' valence image. The tables show odds ratio coefficients where numbers between zero and one are interpreted as negative effect, one means no effect, and numbers larger than one are interpreted as percental increase in probability. The probability of voting for a party decreases as the distance between a voter's self-placement and the experts' placement of a focal party increases. In Table 2, voters' decision rules include two additional positional dimensions-proximity on the level of immigration and European integration. ${ }^{9}$ The coefficients represent the change in the odds of voting for one party over another given a one unit increase in the proximity differential between the voter and the two parties. For example, a voter who is exactly in the middle between

\footnotetext{
${ }^{9}$ In the appendix I estimate a variety of decision rules as robustness checks. These models include placing parties at respondents' idiosyncratic placements, changing voters' decision rule to a squared loss function (with and without the linear term), and adding a directional component to the model. In all the models, the substantive conclusions of this paper hold.
} 


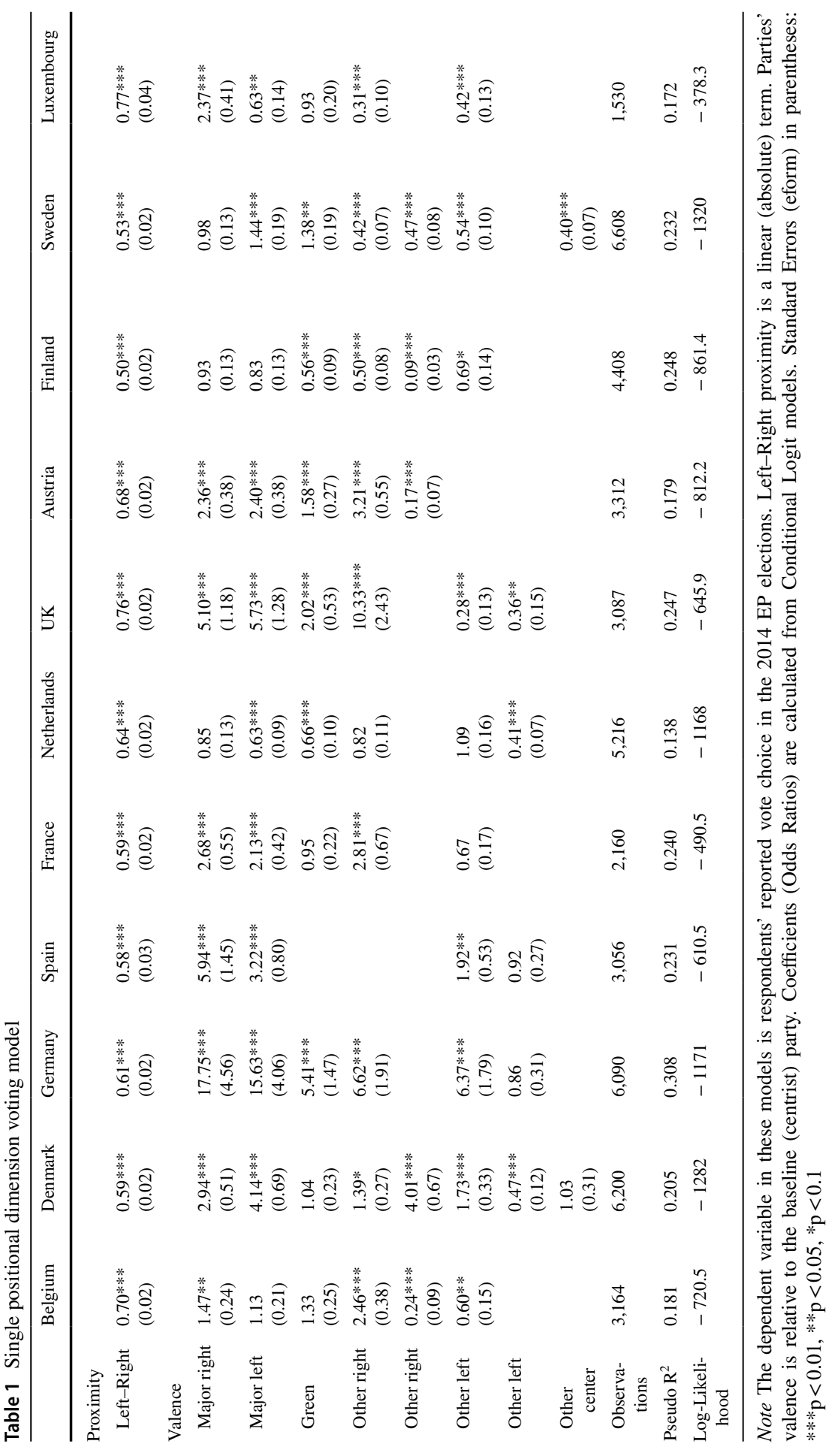




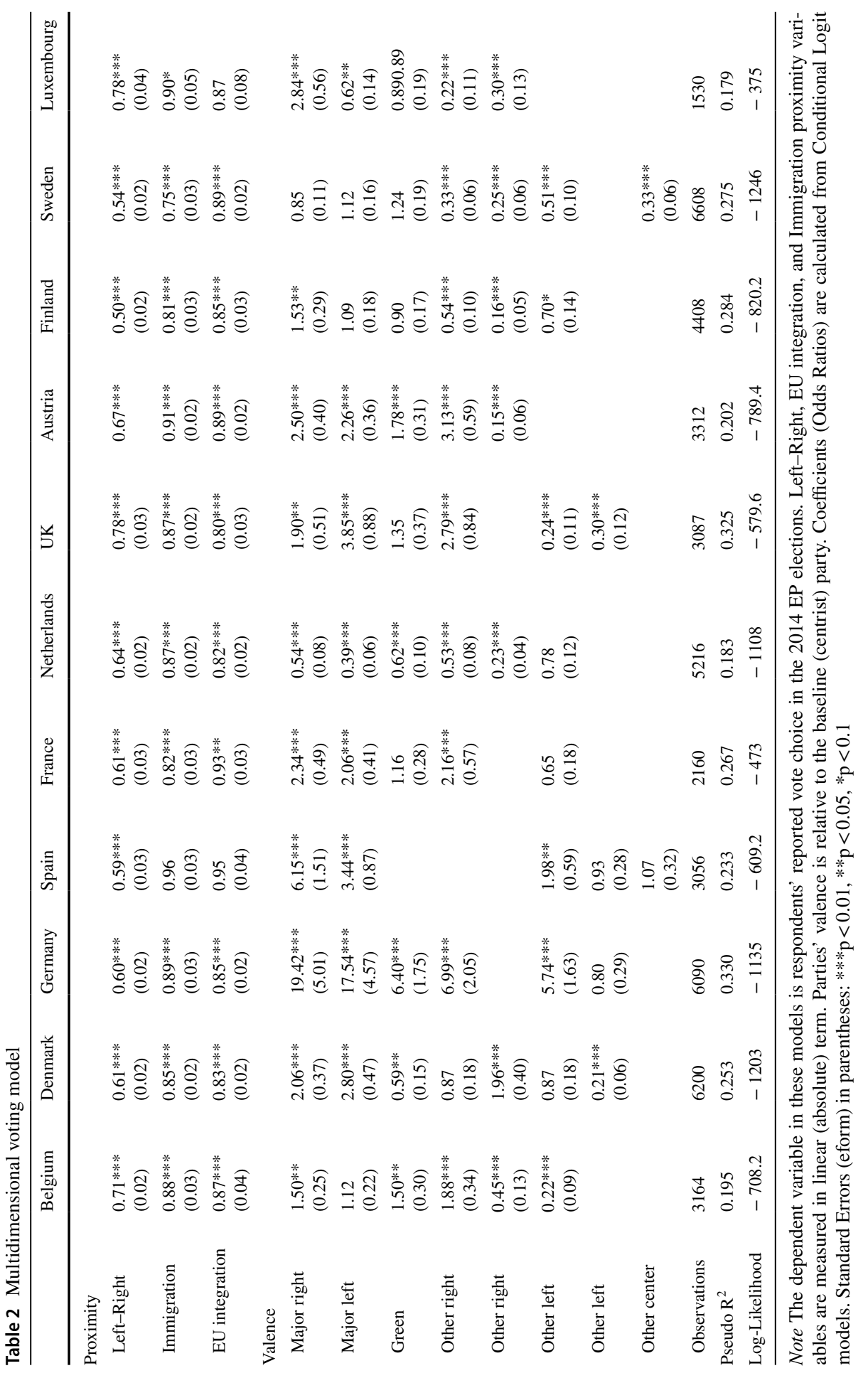


party A and party B (i.e. the proximity differential equals zero) is equally likely to vote for A as for B, regardless of the coefficient. But, if the voter is one unit closer to party $\mathrm{A}$ than to party $\mathrm{B}$, and the coefficient on the proximity variable equals 0.7 , the voter is 30 percent more likely to vote for A over B. The closer the coefficient is to zero, the larger the effect of the distance on the focal dimension on vote choice. The coefficients on the Left-Right proximity variables in Table 1 are very similar to the respective coefficients in Table 2. This implies that the additional dimensions have independent effects on vote choice in EP elections. Moreover, Left-Right proximity has significantly stronger effect on vote choice. Surprisingly, the issue of immigration has no significant effect on vote choice in Spain, and the issue of European integration has no significant effect in Spain and Luxembourg. It is worth noting that the electoral effects of parties' immigration positions might be larger today than in 2014, as the 2014 EP elections preceded the European refugee crisis. Note that in the United Kingdom, European integration is almost as salient as the Left-Right dimension, presumably foreshadowing the turbulent political environment regarding the United Kingdom European Union membership referendum and its aftermath.

In addition to variables measuring issue proximity, both tables include party specific coefficients that estimate parties' perceived valence image relative to the baseline category, which is the largest centrist party in the system. Positive (negative) values on these coefficients imply that the focal party has a valence advantage (disadvantage) over the centrist party. With the exception of the Netherlands, there is at least one party that has a valence advantage over the centrist party, in both the unidimensional (Table 1) and multidimensional (Table 2) models.

To understand the information conveyed in these tables we can examine the case of France. The party of interest in this case is the Democratic Movement (MoDem), a small centrist party that received almost $10 \%$ of the votes and 7 out of the 74 French seats in the 2014 EP elections. In Table 1, the coefficient for the major-Right party, The Union for a Popular Movement (UMP), in France is 2.68, implying that a voter who is indifferent between MoDem and UMP on Left-Right is almost 3 times more likely to vote for the major-Right party over the centrist one. Similarly, the coefficient on the major-Left party (Socialist Party-SP) is 2.13, implying that a voter who is equally distant between MoDem and SP is more than twice as likely to vote for SP over MoDem. These substantive results hold in the multidimensional model as well; a voter who is indifferent between the parties on all three dimensions is 2.34 more likely to vote for UMP over MoDem, and 2.06 times more likely to vote for SP over MoDem.

The data and analyses suggest that most centrist parties are largely valence disadvantaged relative to either the major party on the right or on the left (and relative to both in half of the cases). Centrist parties are also valence disadvantaged relative to some other parties. This is consistent with previous research on centrist parties in national elections (Zur 2019a) and with robustness checks shown in the appendix. Continuing with the example of France, MoDem was valence disadvantaged relative to the National Front as well. The centrist party in the Netherlands (D66) is a counter example; this party is not valence disadvantaged relative to any of the parties. In the Netherlands all of the party specific coefficients are between zero and one, 


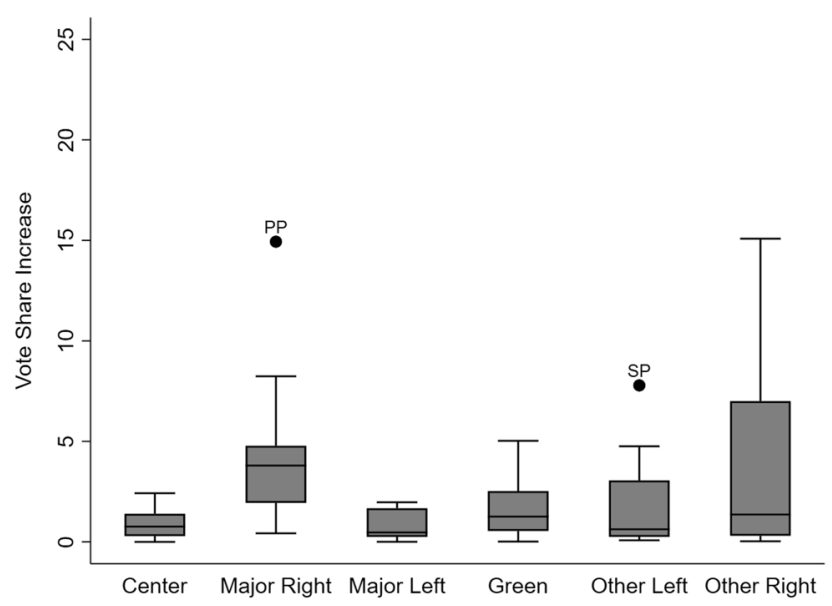

Fig. 2 Vote-share growth due to moving to vote-maximizing position. Note boxes show 25th to 75th percentiles of parties' vote-share increase from changing their left-right position (as coded by the CHES) to their computed vote-maximizing position. Each box represents at least 11 party-election simulations

meaning that relative to the D66 party, valence has negative (or insignificant) effect on vote-choice for the focal party. For example, the coefficient on the major-Left is 0.63 (in the unidimensional model) and 0.43 (in the multidimensional model), implying that a voter who is indifferent between D66 and the Labour Party (PvdA) is roughly twice as likely to vote for the former party.

The results of both the unidimensional and three-dimensional models are consistent with the first hypothesis. Centrist parties are, for the most part, valence disadvantaged. This disadvantage illuminates the electoral failures of centrist parties in EP elections. Given their valence disadvantage centrist parties have limited positional strategy they can employ to compensate for their valence disadvantage. Based on the results in Tables 1 and 2, I have computed the changes to parties' expected vote-shares as a function of unilateral changes in their policy positions, while holding everything else constant. This simulation method has been used to test how election results would change due to a variety of counterfactual scenarios of interest. Put simply, these simulations ask by how much a party's vote-share would increase if it could take the most electorally advantageous positions, while everything else stays the same. Under these counterfactual scenarios, parties' vote-shares must increase, but the magnitude of the increase should vary among parties and party groups.

The scenario simulated in Fig. 2 is the change of parties' expected vote-shares as a function of the focal party unilaterally shifting from its Left-Right position to the position that maximizes its prospective vote-share. Before comparing centrist parties to the other groups, note that when parties move from their perceived to their votemaximizing position on the Left-Right spectrum their electoral gains are not great. The average vote-share gain in this scenario is only $2.3 \%$ and the median is $1.2 \%$.

Moving to our group of interest, centrist parties gain on average less than $1 \%$. The differences in gains between centrist and the right-wing parties (both major and minor) are statistically significant at the $\mathrm{p}<0.05$ level. This finding can be 


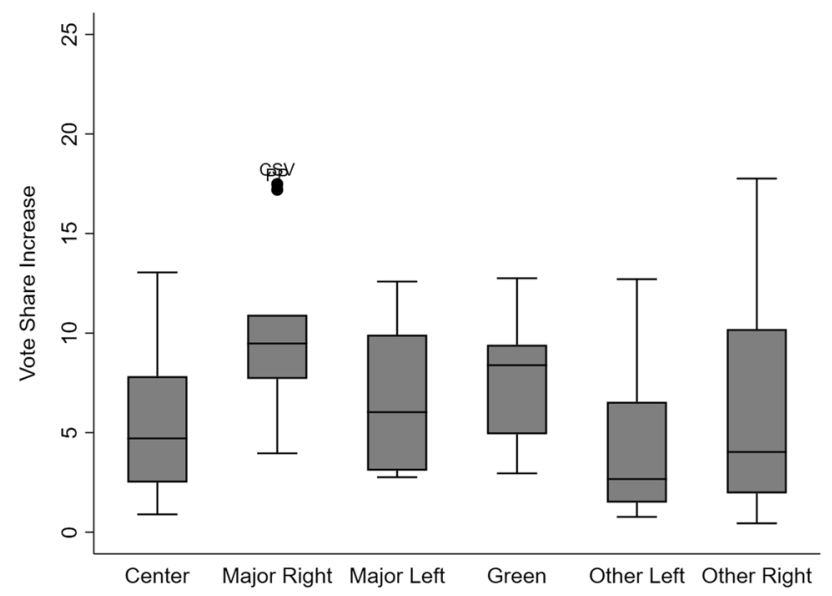

Fig. 3 Growth due to moving to vote-maximizing positions in 3-dimensional space. Note Boxes show 25 th to 75 th percentiles of parties' vote-share increase from changing their left-right, immigration and European integration positions (as coded by the CHES) to their computed vote-maximizing position. Each box represents at least 11 party-election simulations

explained by the observation that Right-wing parties tend to take policy positions that are relatively further away from their vote-maximizing positions. This result supports Hypothesis 2; centrist parties have no Left-Right positional strategy that can increase their vote-share substantially.

The simulations presented in Fig. 3 are computed from the counterfactual scenario where each party unilaterally shifts its Left-Right position from its perceived to vote-maximizing position, then shifts its position on Immigration, and lastly moves to its vote-maximizing position on the European integration issue. Under this scenario, parties' average gains are much greater than under the scenario where the parties can shift their position only on the Left-Right continuum. The average vote-share increase in this case for centrist parties is $5.4 \%$, while the average for all other parties is $6.4 \%$. Moreover, the gains of both major-Right and Green parties are significantly larger than those of centrist parties. This result supports the third hypothesis; centrist parties can modestly increase their voteshare using a multidimensional strategy. It is important to note, however, that these results are based on a counterfactual scenario were centrist parties have to sharply change their policy positions, especially on the issue of European integration. While there are examples of non-centrist parties changing their perceived positions (see Adams et al. 2012a, b; Seeberg et al. 2017), such change might involve further deterioration of their valence image (Fernandez-Vazques 2019; Tomz and Van Houweling 2012). Moreover, it is hard to believe that parties in general, and centrist parties more specifically, are able to communicate to voters such sharp changes in their policy position (Adams 2012; Spoon and Klüver 2017).

The multidimensional disadvantages of centrist parties are shown by the comparison between Figs. 2 and 3. First, centrist parties cannot significantly increase their 
Table 3 Distance between parties positions and votemaximizing positions

\begin{tabular}{lllll}
\hline & Left-right & Immigration & $\begin{array}{l}\text { European } \\
\text { Integration }\end{array}$ & Cumulative \\
\hline Center & 1.05 & 1.51 & 4.79 & 7.35 \\
Major right & 1.88 & 1.44 & 3.97 & 7.30 \\
Major left & 0.82 & 1.18 & 4.13 & 6.14 \\
Green & 1.67 & 3.48 & 4.17 & 9.31 \\
Other Right & 2.48 & 2.65 & 2.42 & 7.55 \\
Other left & 2.39 & 3.00 & 2.64 & 8.04 \\
\hline
\end{tabular}

vote-shares by altering their position on the most salient dimension in EP elections (Left-Right). That is, they cannot take any Left-Right position that will compensate for their unfavorable image of valence.

Second, moving to analysis of multiple dimensions, centrist parties' additional gains are smaller than those of moderate parties both on the Left and Right. Therefore, a multidimensional vote-maximizing strategy would increase centrist parties' vote-shares, but it is insufficient to compensate for their low valence image. Put differently, even when parties are given a hypothetical chance to take the perfect set of policy positions, centrist parties cannot improve their electoral prospects to become the leading parties in the EP. The same logic is evident in Table 3, where the average distance between parties' positions and their vote-maximizing positions is shown. Centrist parties are extremely close to their vote-maximizing position on Left-Right (second only to major-Left parties), thus altering their position yields only marginal increase despite being the most salient dimension. On the other hand, centrist parties have a long distance to travel between their perceived positions to their vote-maximizing positions on European integration (the least salient dimension). Thus, even if centrist parties could communicate such a sharp change in their positions toward more neutral or even anti-EU stands, changing positions would not result in a large increase of centrist parties' vote-share.

Given that centrist parties have no real positional strategy they can pursue in order to increase their vote-share to a meaningful extent, what should they do? The next set of analyses shows how parties' vote-shares would change as a function of changes in their valence image. Figure 4 displays parties' vote-share increase under the hypothetical scenario where parties' valence image is improved by one unit, while everything else remains constant. One-unit change in parties' valence image is a realistic change as it is roughly the median observed valence change between elections (Zur 2019a). The one-unit increase in valence image is also a little over one standard deviation of the observed median valence value in the data used in this paper (i.e. Tables 1 and 2).

Under the scenario where parties increase their perceived valence image by one unit, all parties' vote-shares increase more dramatically than under the scenario where the move from their announced positions to their vote-maximizing positions on all three dimensions. The average vote-share increase for all parties is $12.5 \%$ from improved valence image, while only $6.2 \%$ from altering policy positions. 


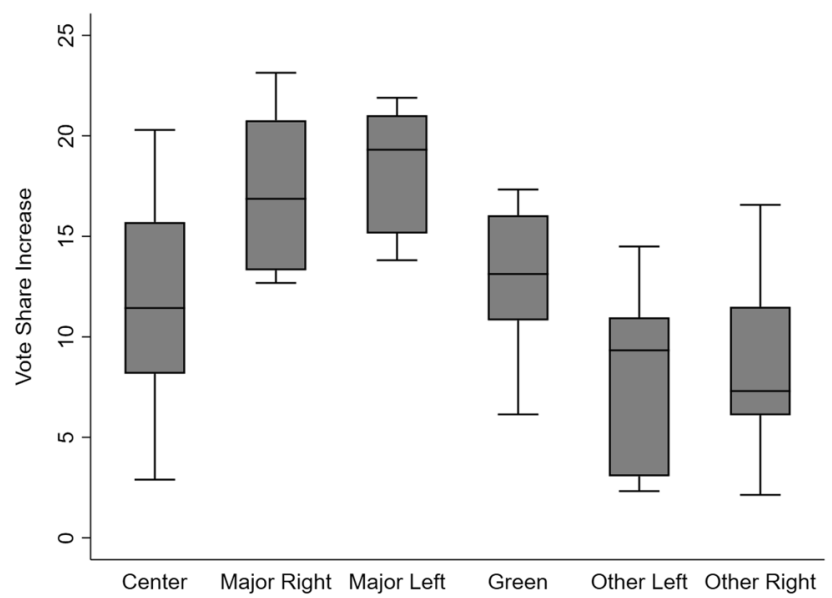

Fig. 4 Vote-share growth due to 1-unit increase in valence. Note Boxes show 25th to 75 th percentiles of parties' vote-share increase from improving their valence image by 1 unit, while holding their policy position and voters' decision rule constant. each box represents at least 11 party-election simulations

Similar results are true for centrist parties that could gain 5.4\% from improving their three-dimensional policy positions, while gaining on average additional $11.7 \%$ by improving their valence image. Despite the substantive gains centrist parties can make by improving their valence image, they are still disadvantaged. This disadvantage is demonstrated by the significantly larger gains major-Left and -Right parties can make by improving their valence image in the same magnitude. On average, both major-Left and major-Right parties can increase their vote-shares by $18.7 \%$ and $17.7 \%$ (respectively) under the counterfactual scenario where their valence image is improved by one unit. These results are consistent with Hypothesis 4; while centrist parties' most meaningful path toward electoral growth is improving their valence image, this growth is smaller than the growth of major-Left and major-Right parties under the same conditions.

\section{Conclusion}

Centrist parties in Western democracies in recent years compete for votes under very fertile conditions; their Left-Right position is extremely popular, and they are not squeezed by other parties. The data used in this paper show that more than a quarter of voters place a centrist party closest to their ideological position, while over $17 \%$ of the voters place themselves closest to the position of a centrist party as perceived by experts. Yet, less than $10 \%$ of these voters voted for a centrist party in the 2014 EP elections. In this paper I explain this phenomenon by arguing that centrist parties encounter three related disadvantages. First, centrist parties are perceived by voters as low valence parties. That is, they are less competent, honest, or unified than their large mainstream counterparts. This valence disadvantage, in turn, motivates voters to vote for parties that might offer less policy-based, but more valence-based utility. 
These results are particularly striking because EP elections are understood as elections in which voters make sincere voting decisions (i.e. they consider issues such as government formation to a lesser extent).

Second, I presented theoretical arguments and empirical analyses to demonstrate that centrist parties are near their vote-maximizing Left-Right position, hence they cannot use spatial strategies to compensate for their low valence, while non-centrist parties typically able to improve their vote-shares by altering their Left-Right position. Moreover, centrist parties' policy positions with respect to immigration, and especially with respect to European integration, are less popular. These positions hurt centrist parties in two ways in the EP elections. First, the salience of these issues makes voters less likely to vote for them. Second, given their negative valence image, announcing more popular EU or immigration positions seems like a useful positional strategy, but it is insufficient to overcome their major rivals on the Left and Right. These findings about the positional disadvantage of centrist parties in EP elections have important implications for national elections. Research has shown that issues that are salient in EP elections are less (or not at all) salient in national elections. The positional strategy (take more popular positions on immigration and EU integration) that centrist parties can use in EP elections might not be very useful in national elections as these issues are less likely to affect voters' decision rule.

Lastly, centrist parties are disadvantaged with respect to their ability to grow by improving their valence image. Despite being the only strategy toward a substantive vote-share growth, improving their valence image would generate gains that are smaller than those of the major mainstream parties under the same conditions. Here again, the implications for national elections are not in favor of centrist parties. If valence is more important in national elections than in the EP elections, centrist parties will have much greater valence gap to close in national elections.

The theoretical argument and the empirical analysis presented in this paper have important implications to the study of political representation and parties' campaign strategies. These results imply that when deciding how to spend their resources, centrist parties should focus on improving their valence image and not on emphasizing their Left-Right policy position, while deemphasizing or moderating their unpopular immigration and EU integration policy positions. First and foremost, the results advance our knowledge about political representation as they suggest that voterparty relations are rational. Parties at the center of the Left-Right spectrum are not weak because voters are "fooled" or misrepresented by the major parties on both the Left and Right, but because voters rationally prefer voting for parties that maximize their valence-based utility over parties that are the most proximate to their positions.

Future research should study the generalizability of these results and their implications to national rather than EP elections. However, the theoretical arguments and the empirical strategy in this paper provide good reasons to believe that the results are indeed generalizable. First, analyzing the EP elections provides the hardest test for the theory because voters in EP elections tend to prioritize immigration and European integration more than they do in national elections, and voters put less emphasis on valence considerations in EP elections relative to national elections. Second, because votes' attention to issues such as government formation and coalition management is irrelevant to EP elections, but 
important in national elections, parties are freer to alter their policy positions in EP elections. If the strategies discussed in this paper are insufficient for centrist parties' electoral success in EP elections, it is hard to believe that they will be sufficient in national elections. Lastly, both the evidence in the Appendix and in the existing literature suggest that the arguments in this paper are generalizable to national elections.

Acknowledgements An earlier version of this article was presented at the 2019 annual meeting of the Midwest Political Science Association. I thank Carlos Algara, Christopher Hare, Ireen Litvak-Zur, Matthew Shugart, the editor, and the anonymous reviewers whose thoughtful comments significantly improved this manuscript. Any remaining errors are my sole responsibility.

Data availability All data and associated files necessary for replicating the analyses contained in this article are posted at the Political Behavior Dataverse and can be accessed at: Zur, Roi, 2020, "Replication Data for: The multidimensional disadvantages of centrist parties", https://doi.org/10.7910/DVN/OWOZS D, Harvard Dataverse, DRAFT VERSION, UNF:6:njM29fT2/Hlqu05nj5xNsA==[fileUNF].

\section{References}

Abney, R., Adams, J., Clark, M., Easton, M., Ezrow, L., Kosmidis, S., \& Neundorf, A. (2013). When does Valence Matter? Heightened valence effects for governing parties during election campaigns. Party Politics, 19(1), 61-82.

Adams, J. (2012). Causes and electoral consequences of party policy shifts in multiparty elections: Theoretical results and empirical evidence. Annual Review of Political Science, 15, 401-419.

Adams, J., Ezrow, L., \& Somer-Topcu, Z. (2011). Is anybody listening? Evidence that voters do not respond to European Parties' policy programmes. American Journal of Political Science, 55(2), $370-382$.

Adams, J., Green, J., \& Milazzo, C. (2012a). Has the British public depolarized along with political elites? An American perspective on British public opinion. Comparative Political Studies, 45(4), 507-530.

Adams, J., \& Merrill, S. I. I. I. (1999). Modeling party strategies and policy representation in multiparty elections: Why are strategies so extreme? American Journal of Political Science, 43(3), 765-791.

Adams, J., \& Merrill, S. (2000). Spatial models of candidate competition and the 1988 French presidential election: Are presidential candidates vote-maximizers? Journal of Politics, 62(3), 729-756.

Adams, J., \& Samuel Merrill, I. I. I. (2005). Candidates' policy platforms and election outcomes: The three faces of policy representation. European Journal of Political Research, 44(6), 899-918.

Adams, J., \& Samuel Merrill, I. I. I. (2009). Policy-seeking parties in a parliamentary democracy with proportional representation: A valence-uncertainty model. British Journal of Political Science, 39(03), 539-558.

Adams, J., Merrill, S., \& Grofman, B. (2005). A Unified Theory of Party Competition: A Cross-National Analysis Integrating Spatial and Behavioral Factors. Cambridge: Cambridge University Press.

Adams, J., Merrill, S., \& Zur, R. (2020). The Spatial-voting model. The SAGE Handbook of Research Methods in Political Science and International Relations. London: Sage.

Adams, J., \& Somer-Topcu, Z. (2009). Moderate now, win votes later: The electoral consequences of parties' policy shifts in 25 postwar democracies. The Journal of Politics, 71(2), 678-692.

Adams, J., de Vries, C., \& Leiter, D. (2012b). "Which voting constituencies reacted to elite depolarization in the Netherlands? An Analysis of the Dutch public's policy beliefs and partisan loyalties, 1986-1998. British Journal of Political Science, 42(1), 81-105.

Alvarez, R. M., \& Nagler, J. (1998). Economics, entitlements and social issues: Voter choice in the 1996 presidential election. American Journal of Political Science, 42(4), 1349-1363.

Bakker, R., Jolly, S., \& Polk, J. (2018). Multidimensional incongruence and vote switching in Europe. Public Choice, 176(1-2), 267-296. 
Bakker, R., Jolly, S., \& Polk, J. (2020). Multidimensional incongruence, political disaffection, and support for anti-establishment parties. Journal of European Public Policy, 27(2), 292-309. https://doi. org/10.1080/13501763.2019.1701534.

Bølstad, J., \& Dinas, E. (2017). A categorization theory of spatial voting: How the center divides the political space. British Journal of Political Science, 47(4), 829-850.

Close, C., \& Delwit, P. (2019). Liberal parties and elections. In E. Van Haute \& C. Close (Eds.), Liberal Parties in Europe. London: Routledge.

Clark, M. (2009). Valence and electoral outcomes in Western Europe, 1976-1998. Electoral Studies, 28(1), 111-122.

Clark, M. (2013). Understanding parties' policy shifts in Western Europe: The role of valence, 19762003. British Journal of Political Science, 44(2), 261-286.

Clark, M. (2014). Does public opinion respond to shifts in party valence? A cross-national analysis of Western Europe, 1976-2002. West European Politics, 37(1), 91-112.

Clark, M., \& Leiter, D. (2014). Does the ideological dispersion of parties mediate the electoral impact of valence? A cross-national study of party support in nine Western European democracies. Comparative Political Studies, 47(2), 171-202.

Dalton, R. J., \& McAllister, I. (2015). Random walk or planned excursion? Continuity and change in the left-right positions of political parties. Comparative Political Studies, 48(6), 759-787.

Downs, A. (1957). An Economic Theory of Democracy. New York: Harper \& Row.

Ezrow, L. (2005). Are moderate parties rewarded in multiparty systems? A pooled analysis of Western European elections, 1984-1998. European Journal of Political Research, 44(6), 881-898.

Fernandez-Vazquez, P. (2019). The credibility of party policy rhetoric survey experimental evidence. The Journal of Politics, 81(1), 309-314.

Green, J., \& Jennings, W. (2012). The dynamics of issue competence and vote for parties in and out of power: An analysis of valence in Britain, 1979-1997. European Journal of Political Research, 51, 469-503.

Green, J., \& Jennings, W. (2017). The Politics of Competence: Parties, Public Opinion and Voters. Cambridge: Cambridge University Press.

Hix, S., \& Marsh, M. (2007). Punishment or protest? Understanding European parliament elections. The Journal of Politics, 69(2), 495-510.

Hobolt, S. B., et al. (2009). A vote against Europe? Explaining defection at the 1999 and 2004 European parliament elections. British Journal of Political Science, 39(1), 93-115.

Hobolt, S. B., \& De Vries, C. (2016). Turning against the Union? The impact of the crisis on the Eurosceptic vote in the 2014 European Parliament elections. Electoral Studies, 44, 504-514.

Hobolt, S. B., \& Spoon, J.-J. (2012). Motivating the European voter: Parties, issues and campaigns in European Parliament elections. European Journal of Political Research, 51(6), 701-727.

Hobolt, S. B., \& Tilley, J. (2016). Fleeing the centre: The rise of challenger parties in the aftermath of the euro crisis. West European Politics, 39(5), 971-991.

Hong, G. (2015). Explaining vote switching to niche parties in the 2009 European Parliament elections. European Union Politics, 16(4), 514-535.

Huckfeldt, K. I., \& Pappi, F. U. (2005). Patterns of disagreement in democratic politics: Comparing Germany, Japan, and the United States. American Journal of Political Science, 49, 497-514.

Johns, R., \& Kölln, A. K. (2020). Moderation and Competence: How a Party's Ideological Position Shapes Its Valence Reputation. American Journal of Political Science, 64(3), 649-663.

Kedar, O. (2005). When moderate voters prefer extreme parties: Policy balancing in parliamentary elections. American Political Science Review, 99(02), 185-199.

Klüver, H., \& Spoon, J. J. (2020). Helping or hurting? How governing as a junior coalition partner influences electoral outcomes. The Journal of Politics, 82(4), 1231-1242.

Macdonald, S. E., Rabinowitz, G., \& Listhaug, O. (2007). Simulating models of issue voting. Political Analysis, 15(4), 406-427.

Matthews, S. A. (1979). A simple direction model of electoral competition. Public Choice, 34(2), $141-156$.

Merrill, S., \& Grofman, B. (1999). A Unified Theory of Voting: Directional and Proximity Spatial Models. Cambridge: Cambridge University Press.

Mondak, J. J. (1995). Competence, integrity, and the electoral success of congressional incumbents. The Journal of Politics, 57(04), 1043-1069. 
Polk, J., et al. (2017). Explaining the salience of anti-elitism and reducing political corruption for political parties in Europe with the 2014 Chapel Hill Expert Survey data. Research \& Politics, 4(1), 7. https://doi.org/10.1177/2053168016686915.

Rabinowitz, G., \& Macdonald, S. E. (1989). A Directional theory of issue voting. American Political Science Review, 83(01), 93-121.

Reif, K., \& Schmitt, H. (1980). Nine second-order national elections: A conceptual framework for the analysis of European Election results. European Journal of Political Research, 8(1), 3-44.

Schmitt, H., Hobolt, S. B., Popa, S. A., \& Teperoglou, E. (2015). European parliament election study 2014, voter study. GESIS Data Archive, Cologne. ZA5160 Data file Version 1.

Schofield, N., \& Sened, I. (2006). Multiparty Democracy: Elections and Legislative. Cambridge: Cambridge University Press.

Seeberg, H. B., Slothuus, R., \& Stubager, R. (2017). Do voters learn? Evidence that voters respond accurately to changes in political parties' policy positions. West European Politics, 40(2), 336-356.

Spoon, J.-J., \& Klüver, H. (2017). Does anybody notice? How policy positions of coalition parties are perceived by voters. European Journal of Political Research, 56(1), 115-132.

Stokes, D. E. (1963). Spatial models of party competition. The American Political Science Review, 57(2), $368-377$.

Spoon, J.-J. (2011). Political Survival of Small Parties in Europe. Michigan: University of Michigan Press.

Stokes, D. (1992). Valence politics. In D. Kavanagh (Ed.), Electoral Politics (pp. 141-162). Oxford: Clarendon Press.

Stone, W. J. (2017). Candidates and Voters: Ideology, Valence, and Representation in US Elections. Cambridge: Cambridge University Press.

Stone, W. J., Maisel, L. S., \& Maestas, C. D. (2004). Quality counts: Extending the strategic politician model of incumbent deterrence. American Journal of Political Science, 48(3), 479-495.

Stone, W. J., \& Simas, E. N. (2010). Candidate valence and ideological positions in US House Elections. American Journal of Political Science, 54(2), 371-388.

Tomz, M., \& Van Houweling, R. P. (2012). “Candidate Repositioning.” Unpublished manuscript, Stanford University and University of California, Berkeley.

Zur, R. (2017). When Valence Crushes: Explaining the Electoral Failure of the German FDP in the 2013 Election. German Politics, 26(3), 380-397.

Zur, R. (2019a). Stuck in the middle; ideology, valence, and the electoral failures of centrist parties. British Journal of Political Science. https://doi.org/10.1017/S0007123419000231.

Zur, R. (2019b). Party survival in parliament: Explaining party durability in lower-house parliaments. European Journal of Political Research, 58, 960-980. 